\title{
Self-medication and non-doctor prescription practices in Pokhara valley, Western Nepal: a questionnaire-based study PR Shankar*1, P Partha ${ }^{2}$ and N Shenoy ${ }^{3}$
}

Address: ${ }^{1}$ Department of Pharmacology, Manipal College of Medical Sciences Pokhara, Nepal, ${ }^{2}$ Department of Medicine, Manipal teaching hospital Pokhara, Nepal and ${ }^{3}$ Department of Community Pharmacy, Manipal teaching hospital Pokhara, Nepal

E-mail: PR Shankar* - pathiyilravi@hotmail.com; P Partha - praveen_partha@hotmail.com; N Shenoy - shenoynagesh@rediffmail.com

*Corresponding author

This article is available from: http://www.biomedcentral.com/I47I-2296/3/17

(C) 2002 Shankar et al; licensee BioMed Central Ltd. This article is published in Open Access: verbatim copying and redistribution of this article are permitted in all media for any purpose, provided this notice is preserved along with the article's original URL.

\begin{abstract}
Background: Self-medication and non-doctor prescribing of drugs is common in developing countries. Complementary and alternative medications, especially herbs, are also commonly used. There are few studies on the use of these medications in Pokhara Valley, Western Nepal.

Methods: Previously briefed seventh semester medical students, using a semi-structured questionnaire, carried out the study on 142 respondents. Demographic information and information on drugs used for self-medication or prescribed by a non-allopathic doctor were collected.

Results: Seventy-six respondents (54\%) were aged between 20 to 39 years. The majority of the respondents $(72 \%)$ stayed within 30 minutes walking distance of a health post/medical store. $59 \%$ of these respondents had taken some form of self-medication in the 6-month period preceding the study. The common reasons given for self-medication were mild illness, previous experience of treating a similar illness, and non-availability of health personnel. $70 \%$ of respondents were prescribed allopathic drugs by a non-allopathic doctor. The compounder and health assistant were common sources of medicines. Paracetamol and antimicrobials were the drugs most commonly prescribed. A significantly higher proportion of young ( $<40$ years) male respondents had used selfmedication than other groups.

Conclusions: Self-medication and non-doctor prescribing are common in the Pokhara valley. In addition to allopathic drugs, herbal remedies were also commonly used for self-medication. Drugs, especially antimicrobials, were not taken for the proper duration. Education to help patients decide on the appropriateness of self-medication is required.
\end{abstract}

\section{Background}

In economically deprived communities, most episodes of illnesses are treated by self-medication $[1,2]$. Due to the hilly terrain in Nepal, the poor socioeconomic status, the high cost of modern medicines and non-availability of doctors in rural areas, difficulties arise in accessing mod- ern healthcare. Drug retail shops frequently serve as the public's first point of contact with the healthcare system [3]. Due to the varying topography and climatic zones ranging from the plains of the 'terai' to the alpine grasslands, a variety of herbs and medicinal plants are found in Nepal that play an important role in self-medication [4]. 
In India, another south Asian country with economic and cultural similarities to Nepal, pharmacists and pharmacy attendants play an important role in fostering self-medication among the public [5]. Combination preparations containing 'hidden' classes of drugs and food supplements or tonics of doubtful value were commonly used in India [6]. Similar results reports have come from other developing countries $[7,8]$. Information on self-medication practices in Nepal outside the Kathmandu valley is lacking.

Non-doctor prescribing of medicines is also common in developing countries [1,2]. A "doctor" in this context is defined as someone who has obtained a bachelor of medicine and bachelor of surgery (MBBS) degree in allopathic medicine. In Nepal, certified health assistants (CHAs) and community health volunteers (CHVs) carry out preventive and curative health activities in rural areas [9]. Complementary and alternative medicine (CAM) practitioners are found in both the rural and urban areas [4]. They occupy an important place in the village community. 'Compounders' who have worked for some time under practitioners in cities and have now set up their own clinic, as well as CHAs and medical shop owners are easily accessible providers of healthcare in such rural areas.

Studies on self-medication patterns and the prevalence of non-doctor prescribing in the Pokhara valley are lacking. Over the last two years in our hospital, we have been seeing an increasing number of patients developing resistance to the commonly used antibiotics. A number of males migrate to India and other countries for employment who, on their visits back home on leave, often bring medicines and knowledge of medicines prescribed in those countries. The population has access to allopathic medicines manufactured either in Nepal or India, ayurvedic medicines, herbal medicines and Tibetan remedies (in some areas). It is important to have baseline data on drug use in this population so that future interventions can be planned and changes documented. Hence the present study was carried out in the first fortnight of $\mathrm{Au}$ gust 2001 in Pokhara sub-metropolitan city and the surrounding villages, where a high prevalence of self and non-doctor prescribing was observed in the subject population.

\section{Methods}

Seventh semester medical students who were briefed beforehand in the first fortnight of August 2001 carried out the study on 142 respondents, using a semi-structured questionnaire. The name, address, age, sex, ethnicity, distance from the nearest road head and distance from the nearest health post/medical store were noted. The respondents were classified as urban or rural. Information regarding the type of medication, illness for which the medication was used and reason for not consulting a doctor was collected for both self-medication and the prescription of allopathic drugs by a non-allopathic doctor. The pattern of drug use over a six-month period preceding the study was noted. In case of drug prescription by a nonallopathic doctor, details about the practitioner and the duration of therapy was also noted. Differences in the proportion of patients taking self-medication and non-doctor prescribed medications between the urban and rural respondents, and depending on the age group of the respondents were analyzed using the $\mathrm{z}$ test of proportions. A ' $P$ ' value of $<0.05$ was taken as statistically significant. Differences in the pattern of drug use between the sexes were also analyzed using the z-test $(\mathrm{p}<0.05)$. The institutional review committee of the Manipal teaching hospital, Pokhara, approved the study.

The study population was drawn from three wards of Pokhara sub-metropolitan city with a total population of 4,870 , and from the villages of Dhampus, Kaskikot and Moujha with a total population of 3,876. Simple random sampling was done to choose the study population. The list of individuals from the three wards and the three villages were obtained and the individuals were selected. The response rate was $63 \%$ overall, but the response rate was much lower for females which skewed the sex distribution. The low response of young females and of rural respondents may be a factor. Some of the respondents were suspicious of the interviewers and thought they would get into problems on answering the questions. As detailed later 'recall bias' may, also, be a factor for not using some of the responses. Young females were reluctant to be questioned by the male volunteers, who mainly interviewed the respondents. Respondents of $<10$ years of age were not included in the study because we were not sure that they would be able to comprehend and respond properly to queries on self-medication.

The questionnaire was administered in Nepalese; an English translation of the proforma used to fill in the collected information is shown in additional file 1 and of the questionnaire used to collect the information is shown in additional file 2. It was first trialed on 15 respondents, broadly corresponding to the population under study. The aims of the study were explained to the students as to what information was being sought from the respondents. We also discussed the concept of self-medication and drug use indicators with the students. The respondents were interviewed in their homes. They often had difficulty in recalling precisely the drug use. In many cases, we had to crosscheck with the medicine packets, tablet strips or medicine bottles kept by the respondents. The unavailability of precise information was one of the reasons that $\sim 10 \%$ of the respondent's replies had to be excluded from the study. 
Table I: Age distribution of respondents

\begin{tabular}{|c|c|c|c|c|c|}
\hline Age group & $\begin{array}{l}\text { No. of respondents } \\
\text { (percentage) }\end{array}$ & Male & Female & Urban & Rural \\
\hline $0-9$ & 0 & 0 & 0 & 0 & 0 \\
\hline $10-19$ & $19(13.4 \%)$ & 15 & 4 & 7 & 12 \\
\hline $20-29$ & $42(29.6 \%)$ & 38 & 4 & 25 & 17 \\
\hline $30-39$ & $34(23.9 \%)$ & 31 & 3 & 18 & 16 \\
\hline $40-49$ & $20(14.1 \%)$ & 16 & 4 & 10 & 10 \\
\hline $50-59$ & $19(13.4 \%)$ & 13 & 6 & 11 & 8 \\
\hline$\geq 60$ & $8(5.6 \%)$ & 4 & 4 & 4 & 4 \\
\hline Total & 142 & 117 & 25 & 75 & 67 \\
\hline
\end{tabular}

Table 2: Distance of the respondents houses from the nearest road head (minutes of walking)

\begin{tabular}{ll}
\hline Distance in minutes & No. of respondents (percentage) \\
\hline$<10$ & $77(54.2)$ \\
$10-29$ & $13(9.1)$ \\
$30-59$ & $13(9.1)$ \\
$60-119$ & $12(8.4)$ \\
$\geq 120$ & $27(19)$ \\
Total & 142 \\
\hline
\end{tabular}

$89 \%$ of the respondents living at greater than 10 minutes walking distance from a road head were living in a rural area

The aims of our study were to:

1) obtain baseline data on self and non-doctor prescribing in Pokhara city and the three surrounding villages

2) obtain information on the factors influencing selfmedication and non-doctor prescribing and

3) note any association of self-medication and non-doctor prescribing with demographic factors.

\section{Results}

One hundred and forty two respondents were covered during the study period. The age distribution of the respondents is shown in table 1 . Seventy-six of the 142 respondents (53\%) were aged between the ages of 20 to 39 years. Seventy-five of the 142 respondents resided in an urban area while the rest were residing in villages. One hundred and seventeen respondents (82\%) were male and the rest were females. The low response rate of females $(24 \%)$ was a major reason for this skewed sex distribution.
Thirty-nine of the 142 respondents $(27 \%)$ were farmers while 33 respondents (23\%) were students. Eighteen respondents $(13 \%)$ were employed in the army or were exservicemen, the rest (37\%) were engaged in other occupations. The commonest ethnic/caste group encountered in the survey was Brahmins $54(38 \%)$. The other common groups were Chettris $36(25 \%)$ and Gurungs 29 (20\%). Other ethnic groups like Newars, Puns and Magars accounted for the remaining $16 \%$. Though the overall distribution was skewed the distribution of males and females in the urban and rural populations were comparable. In the age group 10-19 only one woman responded from a rural area while three women responded from urban areas.

Table 2 shows the distance of the respondents' houses from the nearest road head. The time taken in minutes by an average person to walk the distance was employed as the basis for comparison. Seventy-seven respondents $(54 \%)$ stayed within 10 min walk from a road head. A similar criterion was used to measure the distance from the nearest health post/medical store. Fifty-two respondents stayed within 10 min walking distance from a health post/medical store, 50 respondents were located within 10 to 30 min walking distance; 23 were at a distance of 30 to $60 \mathrm{~min}$; 7 stayed within 1 to $2 \mathrm{~h}$ walk from a health post/medical store; 10 were over $2 \mathrm{~h}$ walking distance away.

Eighty-four of the 142 respondents (59\%) had taken some form of self-medication during the 6-month period preceding the study. Table 3 shows the drugs/drug groups commonly used for self-medication. 160 drugs were consumed by the 84 respondents, who had used drugs for self-medication in the preceding 6 months giving an average of 1.9 drugs per person per six months. The average number of drugs consumed by the 142 respondents was 1.13 per person per six months. The commonest drug used was paracetamol in 69 instances $(43 \%)$ followed by 
Table 3: Frequency of drugs/drug groups used by the respondents for self-medication

\begin{tabular}{ll}
\hline Drug/drug group & Frequency of usage \\
\hline & \\
Paracetamol & $69(43.1)$ \\
Other NSAIDs & $37(23.1)$ \\
Cold remedies & $17(10.6)$ \\
Antacids & $10(6.2)$ \\
Herbs & $14(8.7)$ \\
Others & $13(8.1)$ \\
Total & 160 \\
& \\
\hline
\end{tabular}

some other analgesic in 37 instances (23\%). The use of antacids as self-medication was low (6\%). Herbs were also used for self-medication by the respondents [14 out of the total of 160 drugs used $(9 \%)]$. Headache and fever were the most common indications for self-medication, accounting for $60 \%$ of the illnesses requiring self-medication. Self-medication was commonly started once the headache or fever did not come down by itself within 24 $\mathrm{h}$. Fever was associated with body ache in 4 instances and with diarrhea in 3 instances. Drugs were used for selfmedication in $84 \%$ of headaches and $69 \%$ of fevers.

The reasons given for self-medication were analyzed. Thirty-six respondents $(25 \%)$ felt that the illness was too mild and did not require the services of a doctor. Nineteen $\%$ of the respondents felt that they had previous experience of treating a similar illness and even if they go to a doctor they will be prescribed similar medications. Non-availability of a doctor was also cited as a reason for self-medication.

One hundred of the 142 respondents (70\%) were prescribed allopathic drugs by a non-allopathic doctor during the preceding 6 months. The common sources of nondoctor prescription were the compounder in 51 instances and the certified health assistant (CHA) in 42 instances. Drugs obtained from the medical store by the patient without a proper prescription were classified as self-medication. A total of 150 drugs were prescribed over the preceding six-month period. The most commonly prescribed drug was paracetamol [ 33 out of the total of 150 drugs $(22 \%)]$ followed by antimicrobials [16 out of the total of 150 drugs $(11 \%)] .27$ patients did not recall the drugs which were prescribed. The compounders, traditional medicine practitioners and the health assistants gave detailed information to the patients regarding the medications and also about other health protection measures.
Table 4: Differences in the proportion of respondents using selfmedication according to place of residence, gender and age

\begin{tabular}{ll}
\hline Respondent characteristics & $\begin{array}{l}\text { Proportion using self- } \\
\text { medication }\end{array}$ \\
\hline Urban & \\
Rural & 0.65 \\
Male & 0.5 \\
Female & $0.64^{*}$ \\
Age $<40$ years & 0.4 \\
Age $\geq 40$ years & $0.7^{* *}$ \\
& 0.42 \\
\hline
\end{tabular}

$* z=2.22, \mathrm{p}<0.05$, compared to female respondents $* * z=4.84, \mathrm{p}<$ 0.05 , compared to respondents aged $\geq 40$ years

Fever and headache were the commonest reasons for nondoctor prescribing accounting for $46 \%$ of the cases. Nonaccessibility of the doctor was cited as the commonest cause for non-doctor prescribing. Other reasons cited were: visiting the doctor seemed unnecessary for mild illnesses $(23 \%)$, and visits to doctors could be expensive $(11 \%)$.

Table 4 shows the distribution of respondents using selfmedication according to place of residence (urban or rural), sex and age. The proportion of male patients using self-medication was significantly higher than the proportion of females $(P<0.05)$. A significantly higher proportion of respondents aged below 40 years had used selfmedication when compared to those above or equal to 40 years of age. However, the two groups were not balanced with respect to socioeconomic status, education and frequency of illness, and therefore it is difficult to extrapolate from these findings. The male respondents were economically independent compared to the females. Illness appeared to be more frequent among males but could not be verified statistically from the present study. There were no significant differences in the proportion of respondents, according to gender, age or place of residence, who were prescribed allopathic drugs by a non-allopathic doctor.

\section{Discussion}

Self-medication can be defined as obtaining and consuming drugs without the advice of a physician either for diagnosis, prescription or surveillance of treatment [11]. In Nepal, qualified MBBS doctors are often not willing to go to the villages for various reasons and hence the rural people often turn to CAM practitioners, CHAs and CHVs for medical aid. The health posts and the primary health centres in the rural areas are manned by CHAs. The doctor-patient ratio in Nepal is very low [12]. In the past decade a number of medical colleges have been established and the ratio is expected to improve. 
In our study the rate of response of females, especially of the younger age groups, were low and hence the age and sex distribution of our study population was skewed compared to the demography of Kaski district [12]. Distance plays a vital role in the use of health facilities [10]. Our study shows, however, that urban respondents were more frequent users of self-medication (Table 4); further studies will be needed to resolve this paradox. Unfortunately the low sample size of our study and poor response of rural females maybe, confounding variables.

Of the respondents, 59\% had taken some form of selfmedication during the preceding six months. In previous studies the prevalence of self-medication varied widely from $95 \%$ to $12.7 \%[13,14]$. Due to the differing socioeconomic profiles and demographic characteristics of the populations studied, it was difficult to compare the results.

Paracetamol and analgesics were the most commonly used class of drugs, which is similar to findings in the literature $[7,15]$. In developing countries. antimicrobials are commonly sold drugs [16]. In concordance with previous results $[8,16]$, our results show that antimicrobials were not commonly used for self-medication, and were mostly obtained on prescription.

The mode of the number of drugs consumed by the 142 respondents was 1 per person per six months. In a crosssectional study in Latin-America [7], the average number of drugs used was 1.23 per person, but the mode of the number of drugs consumed was not available. Also the Latin-American study was done on patients buying medicines from pharmacies, making it difficult to compare with our results.

Factors influencing self-treatment include patient satisfaction with the healthcare provider, cost of the drugs, educational level, socioeconomic factors, age and gender [17]. Decreased healthcare cost may be a major reason in developing countries. Interactions between prescribed drugs and the drugs taken for self-medication is an important risk factor of which healthcare providers must be aware of $[11,17]$.

A greater proportion of urban respondents and respondents aged below the age of 40 years took self-medication during the preceding six-month period. More male patients used self-medication compared to females, contrary to data from Western reports $[14,17]$. The better socioeconomic status of men in Nepal, their better earning power, and the higher educational level are probably among the reasons. However, this is difficult to reconcile with the fact that economic reasons were commonly cited for self-medication. The greater prevalence of self-medication among the younger generation could be due to the better educational level.

Herbs are also used for self-medication, similar to other developing countries $[2,8]$. Herbal medicines are found in the forests around the villages and are also grown in the courtyards of houses. There are also cultural factors in play, since the respondents had been born into a culture were herbal medicines would have been experienced from an early age. Many respondents, while acknowledging the power of modern allopathic medicines, considered herbal remedies the more appropriate treatment of the cause of illness. Elderly persons in the households possessed knowledge of simple herbal remedies for common illnesses and these remedies were usually tried first. The medical shops also commonly stocked herbal and ayurvedic preparations, making these drugs easily accessible. Herbs were considered safe and devoid of adverse effects. This may not always hold true and the possibility of interactions should be kept in mind [18]. Standardization of the herbal preparations used for a particular illness though difficult to achieve should be aimed at.

Due to the difficulty in accessing health care services in Nepal, self-medication is often the simplest option for the patient. Since traditional practitioners are easily accessible, people also turn to them for their healthcare needs. However, traditional practitioners need to be educated about when to refer a patient for more specialized care. They can also help to introduce modern concepts such as immunization among the rural population. Educational intervention to help patients decide on the appropriateness of self-medication may be helpful. Allopathic drugs are commonly prescribed by persons other than MBBS doctors in the study. Due to the low doctor patient ratio and reluctance of doctors to serve in rural areas CHAs man most of the health-posts in Nepal. CHAs undergo a oneyear course after passing their school leaving certificate examination and manage most health problems on their own. Since health posts and sub-health posts are present in most of the villages, rural people often turn to them for their medical needs. The absence of a significant difference in rural versus urban prescribing of allopathic drugs by persons other than an allopathic doctor is surprising, given the concentration of doctors in urban areas in $\mathrm{Ne}$ pal.

Due to various reasons, antimicrobial drugs were only taken for the proper duration in 4 of the 16 instances where they had been prescribed. The average duration for which an antimicrobial was used was 2.78 days. The duration of drug use was arrived at by asking the respondents, and 'recall' bias may be a confounding factor. The duration of use of other drugs was not specifically enquired into, but in general drugs were stopped as symptoms improved. 
Economic constraints were commonly cited as a reason for the premature stoppage of treatment. Development of antimicrobial resistance has to be kept in mind due to this inappropriate use.

Due to the skewed sex distribution of our sample, and the effect of recall bias and other confounding variables, the results may not be truly representative of the population of Pokhara valley. Further studies on the prevalence, the factors influencing and the appropriateness of self and non-doctor prescribing are required. These studies are being planned as study projects in community medicine for the seventh semester students of our institution.

\section{Conclusions}

Self-medication is prevalent in the Pokhara valley with $59 \%$ of respondents using some form of self-medication in the six-month period preceding the study.

Paracetamol and other NSAIDs were the drugs most commonly used for self-medication. Residence in an urban area, male sex and age less than 40 years were associated with increased self-medication. Herbs were also used for self-medication.

Non-doctor prescribing of allopathic drugs was also common (70\% of respondents). The common sources of medicine were the compounder and the health assistant. Fever and headache were the most common reasons for nondoctor prescription.

Drugs especially antimicrobials were not taken for the proper length of time. Education to help patients decide on the appropriateness of self-medication is required. Further studies on the factors influencing self and non-doctor prescribing are required.

\section{Competing interests}

None declared.

\section{Authors' contributions}

PRS designed the questionnaire, analyzed the results and wrote the manuscript. PP helped in designing the questionnaire, briefed the student volunteers, checked on their progress and helped in writing the manuscript. NS participated in the design of the study and helped in the statistical analysis.

All authors read and approved the final manuscript.

\section{Additional material}

\section{Additional file 1}

Title and description of data: The proforma, which was used to record the data, collected from the respondents using the questionnaire Click here for file

[http://www.biomedcentral.com/content/supplementary/14712296-3-17-S1.doc]

\section{Additional file 2}

Title and description of data: English translation of the Nepalese questionnaire administered to the respondents

Click here for file

[http://www.biomedcentral.com/content/supplementary/14712296-3-17-S2.doc]

\section{Acknowledgements}

The following seventh semester students interviewed the respondents and collected the data under our guidance and supervision: Subodh Regmi, Anuj Shrestha, Jiwan Thapa, Kirti Joshi, Ashok Chaudhary, Somnath Chalise and Adarsha Bajracharya. Their help is gratefully acknowledged. Permission to acknowledge their help has been obtained.

We are thankful to Dr. Denys Wheatley of the University of Aberdeen and the Manuscript presentation service for their help in copyediting the manuscript and to the Soros foundation for covering the cost of copyediting.

\section{References}

I. Sclafer J, Slamet LS, de Visscher G: Appropriateness of self-medication: method development and testing in urban Indonesia. J Clin Pharm Ther 1997, 22(4):26I-272

2. Geissler PW, Nokes K, Prince RJ, Achieng RO, Aagaard-Hansen J, Ouma JH: Children and medicines: self-treatment of common illnesses among Luo schoolchildren in western Kenya. Soc Sci Med 2000, 50:177I-1783

3. Kafle KK, Madden JM, Shrestha AD, Karkee SB, Das PL, Pradhan YM, Quick JD: Can licensed drug sellers contribute to safe motherhood? A survey of the treatment of pregnancy related anemia in Nepal. Soc Sci Med 1996, 42(II): 1577-1588

4. Gartoulla RP: Ethnomedicine and other alternative medication practices, a study in medical anthropology in Nepal. PhD thesis, North Bengal university, Darjeeling, India, 1992

5. Kamat VR, Nichter M: Pharmacies, self-medication and pharmaceutical marketing in Bombay, India. Soc Sci Med 1998, 47(6):779-794

6. Greenhalgh T: Drug prescription and self-medication in India: an exploratory survey. Soc Sci Med 1987, 25(3):307-318

7. Drug utilization research group, Latin America: Multicenter study on self-medication and self-prescription in six Latin American countries. Clin Pharm Ther 1997, 61 (4):488-493

8. Osaka R, Nanakorn S: Health care of villagers in northeast Thailand - a health diary study. Kurume Med J 1996, 43(I):49-54

9. Curtale F, Siwakoti B, Lagrosa C, LaRaja M, Guerra R: Improving skills and utilization of community health volunteers in $\mathrm{Ne}$ pal. Soc Sci Med 1995, 40(8): I I I7-I I 25

10. Dhungel B: Accessibility to social services in rural Nepal: $\mathbf{A}$ case study of Kavre district. MA thesis, Asian institute of technology, Bangkok, 1983

II. Montastruc JL, Bagheri H, Geraud T, Lapeyre Mestre M: Pharmacovigilance of self-medication. Therapie 1997, 52(2): I05-I I0

12. Sharma HB, Gautam RP, Vaidya S, Eds: District development profile of Nepal. Kathmandu, Informal sector research and study center 2001

13. Kasilo OJ, Nhachi CF, Mutangadura EF: Epidemiology of household medications in urban Gweru and Harare. Cent Afr J Med 1991, 37(6): |67-17| 
14. Figueiras A, Caamano F, Gestal OJj: Sociodemographic factors related to self-medication in Spain. Eur J Epidemiol 2000, 16(1): 19-26

15. Arrais PS, Coelho HL, Batista MC, Carvalho ML, Righi RE, Arnau JM: Profile of self-medication in Brazil. Rev Saude Publica 1997, 3I(I):7I-77

16. Calva J, Bojalil R: Antibiotic use in a periurban community in Mexico: a household and drugstore survey. Soc Sci Med 1996, 42(8): || $2|-| \mid 28$

17. Hebeeb GE, Gearhart JG: Common patient symptoms: patterns of self-treatment and prevention. J Miss State Med Assoc 1993, 34(6): $179-18 \mid$

18. Ernst $\mathrm{E}:$ Harmless herbs? A review of the recent literature. $A m$ J Med 1998, 104(2): 170-178

\section{Pre-publication history}

The pre-publication history for this paper can be accessed here:

http://www.biomedcentral.com/1471-2296/3/17/prepub

Publish with BioMed Central and every scientist can read your work free of charge

"BioMedcentral will be the most significant development for disseminating the results of biomedical research in our lifetime."

Paul Nurse, Director-General, Imperial Cancer Research Fund

Publish with BMC and your research papers will be:

- available free of charge to the entire biomedical community

- peer reviewed and published immediately upon acceptance

- cited in PubMed and archived on PubMed Central

- yours - you keep the copyright 